\title{
Book Review Section: Introductory Comments
}

With this issue, we embark upon a book review section that will hopefully become a regular feature of Pediatric Neurosurgery. At the outset, we must ask the question, 'What will make a book review for Pediatric Neurosurgery unique - what will set it apart from reviews in general, or 'adult' neurosurgical journals such as Journal ojNeurosurgery or NeurosurgeryT An obvious answer would be an emphasis on evaluating books of interest to the practicing pediatric neurosurgeon, and we will certainly strive to meet this simple criterion.

Yet the book review section should go beyond this. Each text reviewed in Pediatric Neurosurgery should not only provide information of use in the daily practice of pediatric neurosurgery, but should also contribute in some measure to our knowledge of the sciences which lie at the heart of pediatric neurosurgery as a discipline embryology, developmental anatomy and physiology, and the biology of the child's nervous system and the diseases which affect it. This will be the greater purpose of the book reviews section. To this end, we will be soliciting both pediatric neurosurgical texts as well as contributions from related fields - including the relevant pediatric basic and clinical neurosciences, and pediatric medical and surgical disciplines - which advance both the principles and practice of pediatric neurosurgery. To the extent that each book meets the principles outlined above, the authors will receive our accolades. To the extent that each contribution fails to pass muster, we hope to provide a useful critique upon which the authors might improve future editions.

In this context, it is fitting that our inaugural review is of the second edition of Pediatric Neuroimaging by A. James Barkovich. In the preface to the second edition, Prof. Barkovich intones that'... an understanding of the concepts of basic neuroembryology, normal brain development, and neuropathophysiolo-gy are essential for the proper interpretation of pediatric neuroimaging studies ...'. Indeed, these concepts provide the framework upon which the discipline of pediatric neurosurgery is founded, and Pediatric Neuroimaging contributes mightily to our understanding of them.

MarkS. Dias, MD, FACS Bood Reviews Editor

KARGER O1997/S.KargerAG,|Basel
E-Mail karger@akarger.ch Fax +41613061234 http://www.katger.ch 